\title{
An Exploration of the Pre-Tenure and Tenure Process Experiences of Canadian Nursing Faculty
}

Minawatie D. Singh

York University, minsingh@yorku.ca

Linda Patrick

University of Windsor, Ipatric@uwindsor.ca

Beryl Pilkington

York University, bpilking@yorku.ca

Follow this and additional works at: https://qane-afi.casn.ca/journal

Part of the Other Nursing Commons

\section{Recommended Citation}

Singh, Minawatie D.; Patrick, Linda; and Pilkington, Beryl (2016) "An Exploration of the Pre-Tenure and Tenure Process Experiences of Canadian Nursing Faculty," Quality Advancement in Nursing Education - Avancées en formation infirmière: Vol. 2: Iss. 2, Article 2.

DOI: https://doi.org/10.17483/2368-6669.1062

This Article is brought to you for free and open access by Quality Advancement in Nursing Education - Avancées en formation infirmière. It has been accepted for inclusion in Quality Advancement in Nursing Education - Avancées en formation infirmière by an authorized editor of Quality Advancement in Nursing Education - Avancées en formation infirmière. 


\section{An Exploration of the Pre-Tenure and Tenure Process Experiences of Canadian Nursing Faculty}

\section{Cover Page Footnote}

This research was funded by CASN 2012 National Research Scholar Award Presented to Dr Minawatie Singh We would also like to thank Dr Nancy Purdy, Associate Professor, Ryerson University Cette recherche a été financée par le poste de recherche en formation infirmière de l'ACESI 2012, octroyé à la Dre Minawatie Singh. Nous tenons aussi à remercier la Dre Nancy Purdy, Professeure agrégée de la Ryerson University. 


\section{Introduction}

The number of PhD-prepared nurses seeking employment in academia in Canada is not keeping up with the rate of retirements and the demands for new hires in the same settings. The current number of vacancies is expected to grow over the coming decade as an aging professoriate prepares to leave full-time employment. The mentoring of newly hired professors will become a critical issue for administrators in an increasingly competitive environment and for educators seeking supportive environments to facilitate their successful integration as scholars. Literature exists on organizational culture (Cameron \& Quinn, 1999; Johnson, 2009; Tourangeau et al., 2012), psychological empowerment (Baker, Fitzpatrick, \& Griffin, 2009; Spreitzer, 1995; Thomas \& Velthouse, cited in Spreitzer, 1995, p. 1443), and structural empowerment (Hebenstreit, 2012). Less is known about the overarching question for our study about how organizational culture and the perceived level of psychological and structural empowerment associated with one's work environment impact nursing faculty (Singh, Pilkington, \& Patrick, 2014).

The researchers conducted a mixed methods study combining an online survey and semistructured interviews with participants agreeable to be contacted by phone after completing the survey. The individual interviews enabled the researchers to explore in greater depth two research questions: (1) What are the perceived barriers and enablers of empowering work environments? and (2) What is the current state of mentorship according to the individuals participating in the telephone interviews? In this article, we report in greater depth the findings from the semi-structured interviews.

\section{Background}

Colleges and universities across Canada self-determine what the criteria will be for granting permanence or tenure to their professoriate-most often after a period of probation that varies in length from institution to institution. Achieving tenure or permanence provides individual professors with job security and is a highly valued achievement in academia. The preferred terminal degree required to fill professorial tenure track positions in Canadian university nursing programs is a doctorate. A joint national survey, conducted by the Canadian Nurses Association (CNA) and Canadian Association of Schools of Nursing (CASN) (2013), reported a decrease of $25.8 \%$ in the number of doctoral graduates in Canada between 2011 and 2012. The actual number of graduates decreased to 66 in 2012 compared to 89 in 2011 . Faculty recruitment and retirement statistics from the same report are equally concerning, with Canadian schools of nursing not being able to fill 78 full-time positions in 2013. The impact of both the smaller pool of qualified applicants and the faculty shortage will contribute to a competitive environment among schools trying to fill vacancies. Also, within this context, it is important to consider other competing demands for PhD prepared nurses outside of academia. In 2015, the American Association of Colleges of Nursing (AACN) cited, "higher compensation in clinical and private-sector settings" (p. 2) as the reason for nurse educators either leaving teaching or not being attracted to teaching positions in the first place.

The work environment for new nursing faculty is often very stressful as they adjust to the many pressures of academia that include teaching responsibilities, research, publishing, and service (Baker, Fitzpatrick, \& Griffin, 2009). The challenge for academic administrators is to retain qualified faculty by facilitating their successful role integration as scholars. While Baker et al. (2009) identified psychological empowerment to be highly correlated with job satisfaction, 
less is understood about how culture and structural and psychological empowerment together support the success of new faculty members in their academic work.

\title{
Method
}

\begin{abstract}
Aims
The aims of the qualitative phase of this mixed methods study were to gain a deeper understanding of (a) empowering work environments, and (b) the mentoring experiences of the individuals interviewed.

\section{Design}

A two-phased explanatory sequential mixed methods design (QUAN->qual) was used (Creswell \& Plano Clark, 2007). Phase one consisted of an online national survey and the second phase involved qualitative inquiry to expand upon and explain the survey findings in greater depth. According to Connelly (2009), the benefit of this approach is to "draw on the strengths and minimize the weaknesses of both types of research" (p. 9).
\end{abstract}

\section{Ethical Considerations}

Ethics approval was obtained by the researchers from their respective human research ethics boards prior to beginning the study. The researcher conducting the initial steps to upload the transcripts into the data analysis software did not conduct any of the telephone interviews or transcribe any audio recorded interviews. This step ensured that none of the participants were known to or worked at the same institution as this researcher, who has an administrative position.

\section{Participants}

Nationwide recruitment was initiated using a non-probability sampling method (convenience sampling) in both official languages via emails sent to school directors and circulated by the Canadian Association of Schools of Nursing (CASN). In phase one of this mixed methods study (Singh et al., 2014) a total of 74 nurse educators responded to the survey, but only $60 \%$ of those who responded answered all of the questions on the survey. The final sample consisted of the 44 respondents who completed the entire survey. At the end of the survey, 14 of the respondents consented to being contacted for the telephone interviews. The final sample who was interviewed was 10.

Participants interviewed were mainly Caucasian (70\%), female (80\%), and educated with a doctorate $(60 \%)$ or a Master's degree $(40 \%)$, and half $(50 \%)$ were tenured. Responses to the questions about achieving tenure from the tenured faculty were retrospective reflections in terms of their pre-tenure experiences. Of the five untenured participants, three were in a tenure-track position and two were hoping to move into the tenure-track after completing a PhD.

\section{Data collection}

The telephone interviews began by obtaining verbal consent from each participant. Telephone interviews were audio recorded and transcribed verbatim. Individual identifiers were removed prior to analysis. The interview questions were (1) what are some of the strategies that build healthy work environments?; (2) what are some of the strategies that help develop a productive research culture?; (3) what would you expect from a mentoring program at your school?; (4) what supports faculty members' needs in gaining tenure and promotion?; and (5) how can your school and university help you? 


\section{Data Analysis}

Qualitative data analysis of the transcripts consisted of a combination of manual coding and the use of NVIVO $9^{\mathrm{TM}}$, a qualitative data analysis computer software program. The software facilitated the audit trail by being a repository for all the raw data, data products, and process notes.

The first step in the data analysis process was to read each transcript in its entirety several times to identify significant statements line by line. Transcripts were then compared between the participants to determine similarities and differences. Relationships between the codes and patterns were identified, and, in the next phase of analysis, themes were identified and named. In addition, when the quantitative data analysis was completed for this mixed methods study, the transcripts were analysed for congruence and description of possible explanations for the survey results. All researchers participated in the qualitative data analysis phase.

\section{Rigor}

An audit trail was maintained throughout the study and team meetings promoted researcher triangulation. The evaluative criteria developed by Lincoln and Guba (1985) were used to ensure trustworthiness. Taped interviews were transcribed and to ensure consistency (confirmability) these transcripts were reviewed by two researchers on the team familiar with qualitative data collection and analysis. Credibility involved reading and rereading the data over a long period of time, reviewing the qualitative data, and member checking. Dependability was achieved through the discussion of themes and subthemes until consensus was reached among the researchers and peers. In the final step, the findings of the data analysis were confirmed with two individuals in tenure-track positions independent from the study participants. This step applied to determining transferability or the degree to which the findings of our study have any meaning for others in a tenure track or newly tenured position.

\section{Qualitative Findings}

Respondents overwhelmingly expressed a desire for a collegial and supportive working environment with clearly articulated policies and a transparent process for achieving tenure in academia. Findings reported below answer the research questions and are organized using the following headings: healthy work environment, strategies that develop a productive research culture, mentorship expectations, and, finally, desired support to achieve academic goals.

\section{Healthy Work Environment}

A healthy work environment was clearly identified as critical to the tenure process. Participants expressed a desire on the part of faculty to be accepted, valued, respected, and acknowledged by their peers for their expertise and their uniqueness. Orientation was viewed as a critical process for easing new faculty into their academic environments. It was suggested that an orientation process encourages better engagement by new faculty. In addition, workshops were deemed desirable to help faculty adjust to their academic responsibilities-especially balancing workload issues and academic advising responsibilities. Also identified as important to a healthy work environment was the availability of ongoing mentorship with role modelling of the expected behaviours by peers to clarify expectations of the workplace. Participants described mentoring support as being on many levels: horizontally, from peers, and vertically, from administration. 


\section{Strategies that Develop a Productive Research Culture}

Participants indicated that tenure-track faculty are most often evaluated in three key areas when they submit their application for tenure or permanence in a university setting. Scholarship and research expectations are not balanced with teaching and service, which can prove daunting for new hires under pressure to achieve tenure within a defined timeline. Engaging in a productive program of research requires discipline to apply for grants, conduct research, present findings at conferences, and publish. Tenure pressures may include additional expectations for obtaining external funding with a consistent record of publications in respected journals as principal or co-investigator and lead author, or having made significant contributions to authorship. Participants described how this can become very daunting for new faculty who are navigating new courses to teach and expectations for service within their school. Time management becomes critical to survival and for achieving work-life balance.

The respondents expressed a desire for "valuing" of research within their work environments along with infrastructure support including release time so that they could devote protected time to their research activities. Mentorship was again identified as critical to creating a productive research culture. For example, one participant conveyed the following:

One of the things our Director did with the intent of making a more productive research culture is she hired a senior scholar and brought in someone with a well-established research program as a consultant and began to create infrastructure resources for use in terms of some administrative support...

One participant commented about the existence of a centrally located Office of Research Services (ORS) which was seen as very supportive within the university culture. The ORS was responsible for communicating when grants become available, assisting with the preparation and editing of grant applications and assisting faculty to set up grant accounts when they receive funding. Stability of support was also identified as important for supporting a research culture and assisting professors to be organised, especially around grant submission and ethics applications, given the stress that is created by deadlines.

\section{Mentorship Expectations}

Mentorship expectations were described as not being limited to the institution at which the faculty member was employed and as both formal and informal. A formal mentorship program might include "matching of mentors with mentees, mentoring around 'process' and not just areas of expertise". Mentoring could also include

meetings with key people like chairs of important committees (e.g. tenure and promotion program directors and coordinators) to explain roles; teaching assignments, provide contact lists of who has taught the course before and a staff person to coordinate the tenure application process.

Mentoring was not limited to one person or the same person over time. Respondents felt that informally connecting with someone "who takes you under their wing" was very desirable and valuable, but also having a list of possible mentors from which to personally select was equally useful. The formal pairing of new faculty with an established faculty member during the orientation process was viewed as appreciated, but this mentor may not necessarily be the one who continues over time or with research mentoring. Respondents also expressed that a positive 
mentoring experience contributed to the sustainability in the workplace by creating future mentors in an ongoing culture of support and respect for tenure-track faculty.

Desired Support to Achieve Academic Goals. The final question asked during the telephone interviews sought description of the type of support needed to be successful in a faculty role and achieve tenure and promotion. The respondents identified the need for clear expectations with respect to the tenure and promotion process on the part of the institution, administration, and one's peers. As one participant related,

The whole process is incredibly terrifying, almost punitive, you are working in the best way that you can, and then you are faced with this process. You get a letter saying that you are doing this or that well, can be a double-edged sword, a "gold nugget". It makes people nervous, as you have worked really hard to get to where you want to be and are suddenly told you are not good enough. When you hear of people not getting tenure and promotion, you say well if they did not get it, then you question whether I am good enough.

Information sessions at the university level were identified as important for introducing new nursing faculty to other newly hired faculty across the campus in similar tenure-track academic appointments. Feedback at regular intervals by the faculty member's chair/director was also identified as very important. Feedback could be informal but also included performance evaluations. Performance evaluations provide general feedback related to performance in teaching, research, and service plus identify specific strengths and opportunities for improvement in the tenure journey. The feedback given with regular performance evaluations provides an opportunity for setting clear goals for performance and improvement of weaknesses. Pre-tenure discussions can also be used to set goals for performance and identify additional supports. Participants identified several desirable strategies to further support the tenure candidate. The suggestions included: (1) allowing consistent teaching assignments during the pre-tenure period with limitations on how many new courses are taught; and (2) a reduced teaching load for at least the first year of employment.

The experiences shared by the participants included comments about the need for safe interactions and collegiality and the destructiveness of competition in the workplace. While we did not specifically ask about bullying, the respondents did make references to negative relationships in comments like, "Not that you have to like everybody, but people need to get along". Others referred to a culture of transparency and suggested "making key information available to all", to avoid the use of "information as power". Regarding competition in the workplace, one respondent said:

The biggest challenge of adjusting to academia is the competitiveness. I have been in other environments where it was not like that. When you come up in a system where completion is the key word, that's how you've learned to survive, then to turn that off, or not perpetuate it: Well, I have to pay my dues so they have to pay their dues? It's breaking that cycle.

\section{Discussion}

The findings from this study are reflected in the nursing literature across a number of foci including professional work life, mentoring, faculty incivility, empowerment, role strain, and role transition in academia. A supportive work environment is reportedly a key determinant of 
propensity to stay in a faculty role (Foxall, Megel, Grigsby, \& Billings, 2009), and this also emerged from the national survey portion of our study (Singh et al., 2014). The same workplace qualities that retain faculty influence recruitment (Tourangeau et al., 2012). Our findings are consistent with previous research and are discussed below under the headings of Healthy Work Environment and Empowerment; Role transition, Role strain, and Organizational culture; and Mentoring.

\section{Healthy Work Environment and Empowerment}

We did not directly ask participants about empowerment and job satisfaction in the telephone interviews, but we did enquire about strategies that build a healthy work environment. Responses indicated that a healthy work environment is one that fulfills faculty members' desire to be accepted, valued, respected, and acknowledged by their peers for their expertise and uniqueness, and that this is critical to a successful tenure process. It is conceivable that a healthy work environment is also important to a sense of empowerment among faculty. While the literature has reported the results of many studies examining the relationship between empowerment and nurses' job satisfaction in clinical workplaces, there are fewer studies that have examined empowerment of nursing faculty in their role as academics (Baker et al., 2009; Chung \& Kowalski, 2012). Tenure status did not impact on psychological empowerment or job satisfaction in the study conducted by Baker et al. (2009), but instead they reported that educators who have access to resources to support their faculty work are more satisfied in their academic careers. Similarly, in an earlier study of Canadian college nurse educators, higher levels of workplace (organizational) empowerment was associated with lower levels of dissatisfaction with work (Sarmiento, Laschinger, \& Iwasiw, 2004).

Empowerment in academic settings may be linked to the propensity to innovate. In a study by Hebenstreit (2012), nurse educators' perceptions of structural empowerment were identified as a possible influence over willingness to engage in innovation. Innovative behaviour, according to Hebenstreit, "requires the capacity to change or adapt to new situations" (p. 297). The implications of previous studies on structural empowerment highlight "the importance of developing academic environments with structures that empower nurse educators to accomplish their work" (Hebenstreit, p. 300). Nursing faculty in our study similarly identified the need for more access to resources including research release time, assistance with grant applications and management of grant accounts, information from administrators, and constructive feedback on their performance. Despite the participants' varied reports on the availability of resources to support the tenure journey, a common thread was their willingness to seek out supportive individuals in their workplaces as mentors and role models. Mentors were described as being able to provide assistance with problem-solving and advice on how to meet faculty role expectations including the balancing of multiple and competing demands.

\section{Role Transition, Role Strain, and Organizational Culture}

Our study participants indicated that the demands of the faculty role places enormous stress on them as they transition from the clinical workplace to a college or university setting (which is the career trajectory of most nursing faculty). The transition experiences described by our participants also concur with previous study findings that role strain escalates with increasing complexity and demands of the academic role (Cranford, 2013). Newly hired faculty may choose an academic position following completion of their advanced degree, directly from clinical practice, in a part-time role as a clinical instructor, or after relocating from one institution to 
another. Individual needs for support during the transition period will differ accordingly. It was recognised by our respondents that "one size does not fit all" and that orientation programs should offer a variety of workshops to address the different needs of newly hired faculty.

$\mathrm{PhD}$ programs are varied in their content and graduate expectations; therefore, they may not prepare graduates for teaching roles and responsibilities. Some graduate students may have graduate assistant positions that expose them to clinical teaching, while others may have opportunities to become research assistants. Leaders of doctoral programs acknowledge the need to prepare graduates for more than the research scientist role (Lewallen \& Kohlenberg, 2011). Kelly (2002) found that graduates of doctoral programs seek research careers because they feel inadequately prepared for a teaching role in academia. Both the National League for Nursing (NLN, 2006) and the American Association of Colleges of Nursing (AACN, 2004) recommended that graduates of doctoral programs need more preparation as nurse educators. McDermid, Peters, Daly, and Jackson (2013) explored the transition experience of sessional teachers to new nurse academics. Their findings emphasise the need for formal mentoring strategies, clear expectations and "immersion on entry to the faculty" (p. 53).

Participants in our telephone interviews were from a wide variety of geographical locations across Canada. The institutions that employ them have similar expectations for tenure, but the descriptions of existing support for the tenure journey differed by site. Commonly expressed expectations for leadership within the organization included clear policies with a defined process for tenure and regular performance evaluations with goal setting. The administration was also expected to provide a fair and balanced workload that included release time to establish programs of research and to value mentoring. The desired relationships with colleagues included acceptance and respect with a clear expectation for mentorship and collegiality.

\section{Mentoring}

Our findings confirm the importance of formal and informal mentoring to the academic success of new faculty. Mentoring was seen as critical to creating a productive research culture, and to enabling new faculty to learn the various dimensions of their role as academics. The literature suggests that mentoring is key to recruitment and retention of faculty in nursing. A shortage of nursing faculty in academic settings in the U.S. has existed and been studied over the past decade. The National League for Nursing (2006) endorsed mentoring for nursing faculty throughout their careers as a strategy for recruitment and retention based on a nationwide study on job satisfaction. Chung and Kowalski (2012) followed up with a descriptive study exploring the impact of mentoring on job stress and psychological empowerment on job satisfaction. In their study, $40 \%$ of the respondents were involved in mentoring. The study verified the negative impact that job stress has on job satisfaction reported in earlier studies (Chung \& Kowalski, 2012). Their research also concluded that increased psychological empowerment in nursing faculty improved job satisfaction as previously reported (Chung \& Kowalski, 2012).

Nursing is not the only profession to view mentoring as a strategy to improve career development and job satisfaction for the professoriate. Formal mentorship programs for faculty in pharmacy (Jackevicius et al., 2014) and medicine (Jackson et al., 2003) have been developed over the past decade. Whether informal or formal, mentorship is intentional and nurturing with a deliberate focus on fostering the potential of the person being mentored (Haines, 2003). In the 
study by Jackevicius et al. (2014), it was reported that the mentees were more passive than expected and that this aspect of their mentoring program requires more attention.

\section{Implications for Practice}

Faculty shortages are a threat to academia in Canada as well as in the U.S. The results of our study suggest that newly hired faculty require supportive strategies put into practice to mitigate the stress associated with balancing multiple and competing demands as a novice academic. Retention takes on additional meaning in a competitive field when it is not the salary that dictates whether someone commits to staying in a position.

Strategies to increase retention may include the development of formal mentoring programs for new faculty, especially around the tenure process. The workplace culture desired by new hires includes transparency, valuing of expertise and uniqueness, respect, and a sense of safety. Creating this safe working space will require an investment in existing experienced faculty so that they feel valued for being mentors. Deans and directors may need to offer professional development opportunities via workshops and seminars for their faculty on mentoring strategies and ensure that workloads of experienced faculty take the mentoring role into consideration. DalPezzo and Talley Jett (2010) refer to nursing faculty as a vulnerable population "susceptible to physical, psychological and emotional harm" (p. 132). The participants in our study alluded to an "unsafe" workplace culture as having a negative impact on the tenure journey. The act of seeking out supportive co-workers in a competitive culture can be daunting and potentially destructive, therefore astute administrators should strive to plan ahead for the orientation needs of new faculty. At least initially, a trusted individual should be selected to begin mentoring the new hire on the day-to-day responsibilities, challenges, and opportunities in an academic role.

\section{Limitations of the Study}

Qualitative research findings are not generalizable; furthermore, the small sample size limits representativeness of the findings of the population of Canadian nurse academics. In addition, the interviews were conducted over the phone using previously developed questions and did not facilitate the free flow of narratives by the participants. A future study with faculty conducted face to face or followed over time from hire to tenure may yield richer descriptions of the lived experience and possibly provide insight into interventions that support a successful integration to the workplace.

\section{Conclusion and Recommendations for Future Study}

The need for new faculty in academic settings will continue to grow in the coming years as the current aging professoriate retires and vacancies are created. This presents a two-fold challenge for the nursing profession as the viability of nursing programs nationally will require a strategic plan for both recruitment and retention. The findings from this study addressed perceived barriers and enablers of empowering work environments as well as mentorship expectations and experiences as described by ten faculty members who participated in a telephone interview subsequent to completing an online survey. Future studies should evaluate different mentorship models to determine the best fit for nursing academia. In addition, issues around negative behaviour such as bullying and destructive competition that were identified in this study suggest the need to further explore the impact of faculty incivility on the tenure journey and propensity to leave a position. 


\section{References}

American Association of Colleges of Nursing. (2004). AACN Position Statement on the Practice Doctorate in Nursing October 2004. Washington, DC: Author. Retrieved from http://www.aacn.nche.edu/publications/position/DNPpositionstatement.pdf

American Association of Colleges of Nursing. (2015). Nursing faculty shortage fact sheet. Retrieved from http://aacn.nche.edu/

Baker, S. L., Fitzpatrick, J. J., \& Griffin, M. Q. (2009). Empowerment and job satisfaction in associate degree nurse educators. Nursing Education Perspectives, 32 (4), 234-239. http://dx.doi.org/10.5480/1536-5026-32.4.234

Cameron, K. S., \& Quinn, R. E. (1999). Diagnosing and changing organizational culture. Reading, MA: Addison-Wesley.

Canadian Nurses Association, Canadian Association of Schools of Nursing. (2013). Registered nurses' education in Canada statistics 2011-2012: Registered nurse workforce, Canadian production: Potential new supply. Ottawa, ON: Author.

Chung, C. E., \& Kowalski, S. (2012). Job stress, mentoring, psychological empowerment, and job satisfaction among nursing faculty. Journal of Nursing Education, 51(7), 381-388. http://dx.doi.org/10.3928/01484834-20120509-03

Connelly, L. M. (2009). Mixed methods studies. MEDSURG Nursing, 18(1), 31-32.

Cranford, J. (2013). Bridging the gap: Clinical practice nursing and the effect of role strain on successful role transition and intent to stay in academia. International Journal of Nursing Education Scholarship, 10(1), 1-7. http://dx.doi.org/10.1515/ijnes-2012-0018

Creswell, J., \& Piano Clark, V. (2007). Designing and Conducting Mixed Methods Research. Thousand Oaks, CA: Sage.

DalPezzo, N. K., \& Talley Jett, K. (2010). Nursing faculty: A vulnerable population. Journal of Nursing Education, 49(3), 132-135. http://dx.doi.org/10.3928/01484834-20090915-04

Foxall, M., Megel, M. E., Grigsby, K., \& Billings, J. S. (2009). Faculty retirement: Stemming the tide. Journal of Nursing Education, 48,172-175. http://dx.doi.org/10.3928/0148483420090301-07

Haines, S. T. (2003). Statements: The mentor-protégé relationship. American Journal of Pharmaceutical Education, 67(3), Article 82, 458-464.

Hebenstreit, J. J. (2012). Nurse educator perceptions of structural empowerment and innovative behaviour. Nursing Education Research, 33(5), 297-301. http://dx.doi.org/10.5480/15365026-33.5.297

Jackevicius, C. A., Le, J., Nazer, L., Hess, K., Wang, J., \& Law, A. V. (2014). Faculty development: A formal mentorship program for faculty development. American Journal of Pharmaceutical Education, 78(5), 100. http://dx.doi.org/10.5688/ajpe785100

Johnson, B. (2009). Empowerment of nurse educators through organizational culture. Nursing Education Perspectives, 30(1), 8-13. 
Kelly, C. M. (2002). Investing in the future of nursing education: A cry for action. Nursing Education Perspectives, 23(1), 24-29.

Lewallen, L. P., \& Kohlenberg, E. (2011). Preparing the nurse scientist for academia and industry. Nursing Education Perspectives, 32(1), 22-25.

Lincoln, Y. S., \& Guba, E. G. (1985). Naturalistic Inquiry. Newbury Park, CA: Sage Publications.

McDermid, F., Peters, K., Daly, J., \& Jackson, D. (2013). 'I thought I was just going to teach': Stories of new nurse academics on transitioning from sessional teaching to continuing academic positions. Contemporary Nurse, 45(1), 46-55. http://dx.doi.org/10.5172/conu.2013.3563

National League for Nursing. (2006). Position statement: Mentoring of nurse faculty. Nursing Education Perspectives, 27(2), 110-113.

Singh, M. D., Pilkington, F. B., \& Patrick, L. (2014). Empowerment and mentoring in nursing academia. International Journal of Nursing Education, Scholarship, 11(1), 101-111. http://dx.doi.org/10.1515/ijnes-2013-0070

Spreitzer, G. (1995). Psychological empowerment in the workplace: Dimensions, measurement, and validation. Academy of Management Journal, 38(5), 1442-1462. http://dx.doi.org/10.2307/256865

Spreitzer, G. M., \& Quinn, R. E. (2001). A company of leaders: Five disciplines for unleashing the power in your workforce. San Francisco, CA: Jossey-Bass.

Tourangeau, A., Thomson, H., Saari, M., Widger, K., Ferron, E., \& MacMillan, K. (2012). Determinants of nurse faculty intention to remain employed. Open Journal of Nursing, 2, 254-261. doi:10.4236/ojn.2012.23039. 